\title{
PENINGKATAN KETRAMPILAN MAHASISWA DALAM PENGEMBANGAN GPRS - 3G SURVEILANCE SYSTEM PADA MATA KULIAH KOMUNIKASI BERGERAK DAN SELULER
}

\author{
Ahmad Awaluddin Baiti, Nurkhamid, Totok Sukardiyono, Muslikhin, \& Purno Tri Aji \\ Universitas Negeri Yogyakarta \\ e-mail: aawaluddin@uny.ac.id
}

\begin{abstract}
There is a gap between LPTK graduates and the world of work. This is seen from the basic ability of students to solve electronics cases and translate the challenges into project form. On the other hand the Department of Electronic Engineering Education requires the course of Mobile Communication System and Mobile. Looking at the material needs reinforcement in the effort to absorb the material. This is important because students in the 4th semester have entered a period of concentration in the field of telecommunications but have not had much experience related to the material. This research uses Classroom Action Research design or Classroom Action Research (PTK) with spiral model from Kemmis and Taggart combined with Project Based Learning (PJBL) model. The subject of this class action research is the fourth semester student of Prodi. Electronic Engineering Education FT UNY, with a population of 12 people consisting of 3 women and 9 men located in Telecommunication Laboratory Department of Electronic Engineering Education and Informatics FT UNY. The results of the implementation of Mobile Conversion MK lessons based on Project Based Learning model can improve students' efforts in designing projects. Within four meetings completed one project, with the results of the evaluation ability increased by 1.75 points or $8.28 \%$ equivalent.
\end{abstract}

Keywords: Project Based Learning, Elektronic, Basic skill

\begin{abstract}
ABSTRAK
Terdapat gap antara lulusan LPTK dengan dunia kerja. Hal ini dilihat dari kemampuan dasar mahasiswa untuk menyelesaikan kasus elektronika dan menerjemahkan tantangan ke bentuk proyek. Di sisi lain Jurusan Pendidikan Teknik Elektronika mewajibkan menempuh mata kuliah Sistem Komunikasi Bergerak dan Seluler. Melihat pada materi perlu penguatan dalam upaya penyerapan materi. Hal ini penting karena mahasiswa di semester 4 sudah memasuki masa pengambilan konsentrasi dalam bidang telekomunikasi tetapi belum banyak memiliki pengalaman terkait materi. Penelitan ini menggunakan desain Classroom Action Research atau Penelitian Tindakan Kelas (PTK) dengan model spiral dari Kemmis dan Taggart yang dipadukan dengan model Project Based Learning (PJBL). Subjek penelitian tindakan kelas ini adalah mahasiswa semester empat Prodi. Pendidikan Teknik Elektronika FT UNY, dengan populasi 12 orang terdiri dari 3 perempuan dan 9 laki-laki berlokasi di Laboratorium Telekomunikasi Jurusan Pendidikan Teknik Elektronika dan Informatika FT UNY. Hasil pelaksanaan pembelajaran MK Telekomunikasi Bergerak dan Seluler berbasis model Project Based Learning mampu meningkatkan daya-upaya mahasiswa dalam mendesain proyek. Dalam waktu empat pertemuan menyelesaikan satu proyek, dengan hasil evaluasi kemampuan meningkat 1,75 poin atau setara $8,28 \%$
\end{abstract}

Kata Kunci: Project Based Learning, Elektronika, kemampuan dasar

\section{PENDAHULUAN}

Output Lembaga Pendidikan Tenaga Kependidikan (LPTK) hendaklah selaras dengan waktu, termasuk UNY. Akan tetapi dalam dunia kerja sering terjadi gap yang beberapa diantaranya disebabkan oleh: (1) rendahnya link and match dengan industri; (2) kesenjangan materi ajar; (3) adaptasi alumni yang rendah; dan (4) rendahnya ability dalam penyelesaian proyek. Kemampuan dasar mahasiswa dalam elektronika terletak pada kemampuan mereka dalam penyelesaian kasus elektronika, baik secara parsial maupun kompleks. Kemampuan menterjemahkan tantangan ke bentuk proyek adalah dasar bagi 
mahasiswa agar kompetensi elektronika mereka baik.

Di sisi lain di Jurusan Pendidikan Teknik Elektronika dan Informatika (JPTEI) khususnya di semester empat mewajibkan tempuh Matakuliah (MK) Sistem Komunikasi Bergerak dan Seluler. Pada MK tersebut mengisyaratkan beberapa kompetensi yang harus dikuasai antara lain: Mata kuliah ini menyajikan pembahasan tentang konsep komunikasi nirkabel, perkembangan awal, perencanaan dan struktur telekomunikasi bergerak dan selular. Lebih lanjut akan dibahas alokasi frekuensi, masalah-masalah propagasi dan antena. Materi diperdalam dengan pembahasan jenis-jenis sistem telekomunikasi bergerak meliputi analog dan digital serta komunikasi data melalui selular.Oleh karena itu, perlu usaha lebih untuk memperkuat mahasiswa dalam hal penyerapan materi.

Implementasi mata kuliah

Telekomunikasi Bergeark dan Seluler relatif baru (saat ini tahun kedua) dalam Kurikulum 2014 UNY. Data yang berhasil dihimpun dari pengamatan kuliah minggu pertama hanya ada 2 dari 12 mahasiswa telah mengenal AT Command dan hanya seorang yang pernah membuat proyek berbasis komunikasi selular. Kondisi di atas dirasa perlu mendapat perhatian karena para mahasiswa di semester empat telah masuk pada pegambilan konsentrasi, dalam hal ini bidang telekomuunikasi.

Mencermati paparan di atas, terlihat bahwa baik mahasiswa, materi, media, metode pengajaran pada mata kuliah Telekomunikasi Bergerak dan Seluler harus dapat merangsang mahasiswa untuk meningkatkan keterampilan. Dosen menjadi kunci sukses tercapainya kondisi pembelajaran yang efektif. Kemampuan dosen dalam menyampaikan dan menguasai materi akan berperan dalam tercapainya tujuan rumusan instruksional secara efektif, sehingga peran motode mengajar seorang dosen akan berpengaruh besar secara langsung bagi keberhasilan pembelajaran.
Ada banyak ranah dalam pembelajaran, namun jika disederhanakan hanya ada 3 ranah yaitu kognitif, afektif dan psikomotor. Telekomunikasi Bergerak dan Seluler masuk kedalam ranah psikomotor. Untuk itu metode pembelajaran yang dapat menggunakan metode Project Based Learning (PjBL). Metode ini dinilai selaras dengan karakter matakuliah ini yang dalam proses pembelajar ada interaksi dengan peralatan, gambar, dan labsheet sehingga membentuk hubungan kinestetis. Project Based Learning banyak mengembangkan aspek (1) assessment; (2) design; (3) execute; dan (4) evaluating sehingga cocok untuk MK Telekomunikasi Bergerak dan Seluler. Pernyataan itu diperkuat oleh Masayu (2003:2) yang mengatakan project based learning merupakan pembelajaran hasil interaksi dengan lingkungan, media atau peralatan lain, sehingga dapat diperoleh maximum cummulative goal tercapai melalui praktik atau mencoba.

Hakikat dari MK Telekomunikasi Bergerak dan Seluler bertujuan untuk mempermudah transfer gagasan, membantu menyajikan materi pembelajaran kepada mahasiswa, memantau kemajuan belajarnya atau memilih bahan pembelajaran tambahan yang sesuai dengan kebutuhan belajar mahasiswa secara individual. Berdasarkan pada permasalahan, sangat perlu untuk meningkatkan keterampilan mahasiswa melaui project based learning dengan implementasinya. Selain itu, metode pengajaran oleh dosen pun perlu dikembangkan berdasarkan kondisi dan evaluasi kelas tersebut. Maka merasa penting untuk mengadakan penelitian dengan judul "Peningkatan Keterampilan Mahasiswa dalam Pengembangan Proyek Berbasis GPRS-3G Surveilance System pada MK Komunikasi Bergerak dan Seluler". Penggunaan Project Based Learningtersebut diharapkan mampu mengurangi hambatan-hambatan dan dapat meningkatkan keterampilan mahasiswa. 


\section{METODE}

Penelitan ini menggunakan desain Classroom Action Research atau Penelitian Tindakan Kelas (PTK) dengan model spiral dari Kemmis dan Taggart yang dipadukan dengan model Project Based Learning (PjBL). Mainstream pelaksanaan penelitian menggunakan kerangka PTK, sehingga fungsi dari PJBL akan terlihat pada plan dan act dalam suatu siklus PTK. Alasan penggabungan metode ini untuk menjawab beberapa permasalahan di lapangan terkait MK Telekomunikasi Bergerak dan Seluler untuk mahasiswa semester 4 konsentrasi telekomunikasi, perhatikan Gambar 1.

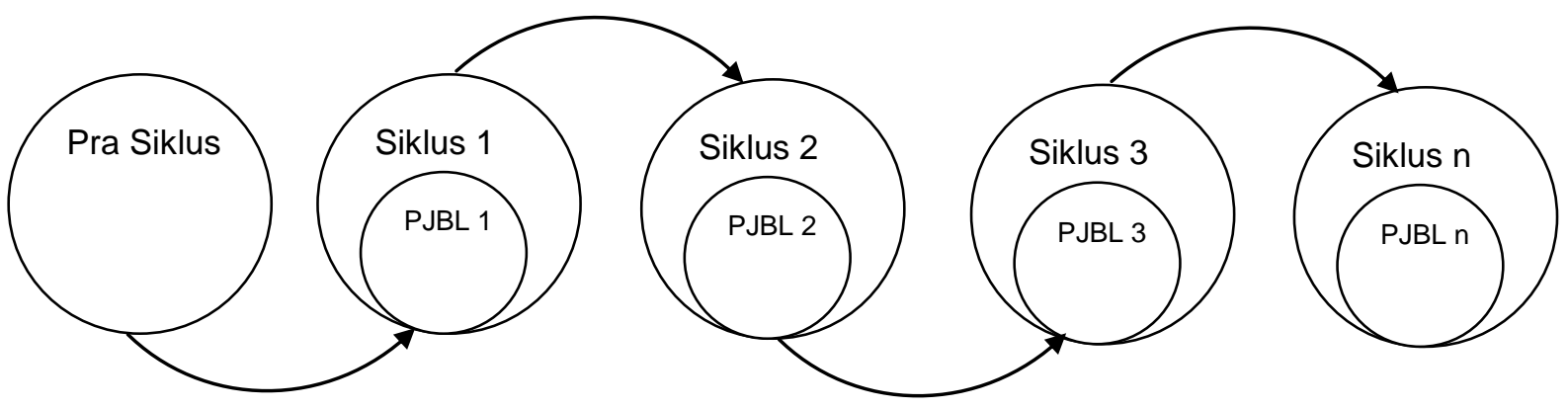

Gambar 1. Siklus PTK yang digabung dengan Project Based Learning

Ada tiga komponen utama dari gambar 3 yaitu: (1) pra siklus; (2) siklus; dan (3) project based learning. Ketiga unsur tersebut menjadi satu kesatuan dan saling terkait antara satu proses dengan proses lainnya dan antara satu siklus 1 hingga siklus ke-n. Subjek penelitian tindakan kelas ini adalah mahasiswa semester empat Prodi. Pendidikan Teknik Elektronika FT UNY, dengan populasi 12 orang terdiri dari 3 perempuan dan 9 laki-laki. Objek penelitian adalah keseluruhan proses peningkatan kemampuan keterampilan menggunakan metode PjBL melalui media pengembangan proyek dalam MK Telekomunikasi Bergerak dan Seluler.

Penelitian tindakan kelas ini akan dilaksanakan di Laboratorium Telekomunikasi, Jurusan PT. Elektronika dan Informatika beralamat di Jl. Colombo No.1 Yogyakarta. Rangkaian kegiatan penelitian dijadwalkan dimulai pada minggu ke 3 Bulan Maret hingga akhir Juli 2017.

Data yang diperoleh dalam penelitian ini berupa hasil observasi, catatan lapangan, dokumen serta wawancara. Dari ketiga instrumen pengumpulan data tersebut ada kelompok data kualitatif (penilaian hasil dokumen) dan data kualitatif (wawancara, observasi, video) oleh karena itu akan dilakukan dua metode analisis data, yaitu analisi data secara kualitatif dan analis data secara kuantitatif. Metode analisis yang dipakai adalah analisis data lapangan model Miles dan Huberman. Analisis dilakukan pada pengambilan data berlangsung sehingga setelah pengumpula data, saat perlakuan/tindakan peneliti dengan cepat akan melakukan analisis. Bila jawaban atau perilaku yang diamati belum sesuai yang diharapkan, maka peneliti dapat melakukan pengulangan dan siklus agar data yang diperoleh benar-benar creadible Mile \& Huberman dalam Sugiyono (2009: 246).

Data yang diperoleh dalam penelitian ini berupa hasil observasi, catatan lapangan, dokumen serta wawancara. Dari ketiga instrumen pengumpulan data tersebut ada kelompok data kualitatif (penilaian hasil dokumen) dan data kualitatif (wawancara, observasi, video) oleh karena itu akan dilakukan dua metode analisis data, yaitu analisi data secara kualitatif dan analis data secara kuantitatif. Metode analisis yang dipakai adalah analisis data lapangan model 
Miles \& Huberman. Analisis dilakukan pada pengambilan data berlangsung sehingga setelah pengumpula data, saat perlakuan/tindakan peneliti dengan cepat akan melakukan analisis. Bila jawaban atau perilaku yang diamati belum sesuai yang diharapkan, maka peneliti dapat melakukan pengulangan dan siklus agar data yang diperoleh benar-benar creadible Mile dan Huberman dalam Sugiyono (2009: 246).

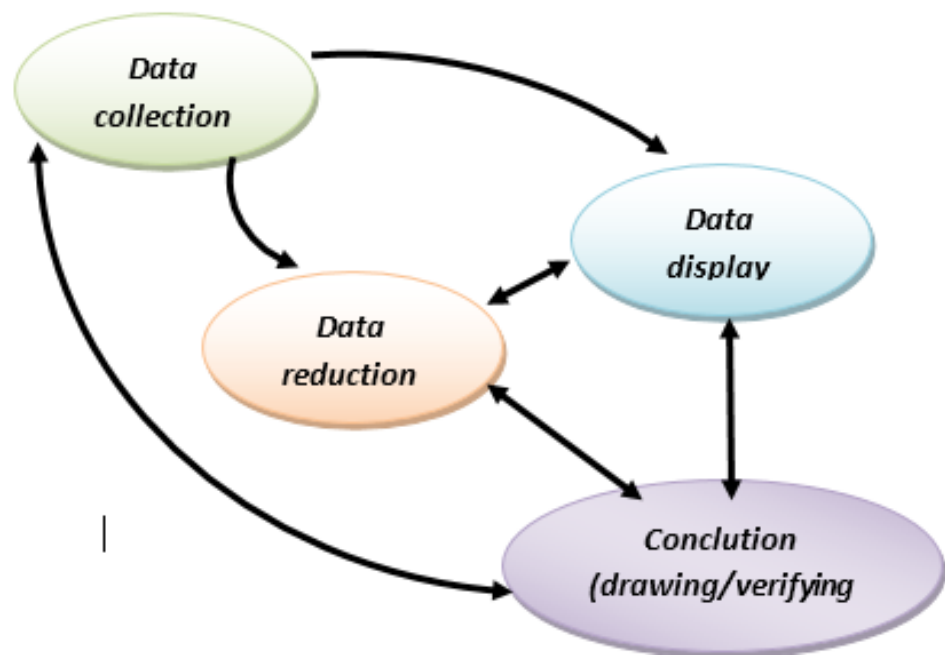

Gambar 2. Komponen dalam analisis data model Miles dan Huberman

Terlihat beberapa komponen di gambar 2 teknis pengolahan data dimulai dari pengumpulan data, reduksi data, lalu disajikan. Meskipun data telah disajikan, tahapan ini masih bagian dari proses yang belum tuntas oleh karena itu masih perlu direduksi lagi hingga dapat ditarik simpulan. Untuk data dokumen hasil penilaian gambar (numerik), digunakan metode analisis kuantitatif sederhana. Pengolahan data hanya dilakukan untuk mengetahui perbandingan peningkatan per siklus, kenaikan indeks dan mengubanhnya ke beberapa grafik dan diagram. Hal ini dipilih karena beberapa indikator peningkatan keterampilan dilihat dari nilai hasil gambar mahasiswa yang sulit dideskripsikan secara deskriptif naratif.

\section{HASIL}

Pelaksanaan pra siklus secara umum digunakan untuk penyamaan persepsi dalam penelitian dan mengetahui kondisi umum kelas. Setidaknya pada pra siklus telah dilakukan dua kali diskusi untuk menyamakan persepsi pada 7 April 2017 dan 5 Mei 2017.
Dari proses penyamaan persepsi tersebut maka didapatkan: (1) dosen menyetujui pelaksanaan pembelajaran menggunakan metode project based learning (PjBL) untuk MK Sistem Telekomunikasi Bergerak dan Seluler; (2) peneliti memberi pemahaman kepada dosen sejawat tentang metode PjBL dan PTK, teknis pelaksanaan serta manjelaskan teknik belajar inquiry dan tutorial; (3) melakukan diskusi materi video yang akan diberikan pada proses awal dan prosedur penilaian hasil; dan (4) tim melakukan pengecekan perangkat pendukung.

Jumlah mahasiswa kelas MK tsb terdiri atas 8 mahasiswa terbagi dalam 5 laki-laki dan 3 perempuan. Matakuliah ini merupakan MK pilihan konsentrasi berbobot 2 SKS. Melalui pengamatan pelaksanaan pembelajaran (5/5/2017 pukul 07.30 - 10.50 WIB), metode yang digunakan dosen mengajar dilakukan secara tutorial kemudian dilanjutkan dengan pendekatan PjBL. Serangkaian kegiatan prasiklus peneliti melakukan penyamaan persepsi, melakukan wawancara dengan dosen MK dan melakukan pengamatan langsung ke kelas yang menjadi subjek penelitian serta mendokumentasikan dalam bentuk video. 
Secara umum pelaksanaan siklus terdiri dari plan, act, observe dan reflect. Tujuan plan pada siklus 1 membentuk kemampuan mahasiswa agar memiliki gambaran tentang produk apa saja yang dapat digunakan untuk menyelesaikan permasalahan setelah melihat tayang video dan juga contoh produk Smart EWS. Hasil pelaksanaan (act) siklus 1 dapat ditempuh dalam 2 pertemuan. Pertemuan 1 dilakukan pada Rabu, tanggal 7 April 2017 dilanjutkan pertemuan 2 pada 14 April 2017. Penggabungan PjBL ke dalam siklus penelitian tindakan, menjadikan beberapa bagian siklus mengalami penambahan unsur. Hasil observasi pada siklus 1 ditunjukkan pada Tabel 1. Tabel 2 menyajikan hasil refleksi dan perbaikan siklus 1 .
Tabel 1. Nilai (rerata kelas) PjBL pada siklus 1

\begin{tabular}{lccc}
\hline \multicolumn{2}{c}{$\begin{array}{c}\text { Komponen } \\
\text { Proyek }\end{array}$} & Siklus & \multicolumn{2}{c}{ Peningkatan } \\
& 1 & Index & $\%$ \\
\hline Kreativitas (45) & 31,30 & n/a & n/a \\
Kebenaran (15) & 12,15 & n/a & n/a \\
Kerapihan (15) & 12,42 & n/a & n/a \\
Waktu (25) & 20,06 & n/a & n/a \\
Nilai Rerata & 75,94 & n/a & n/a \\
\hline
\end{tabular}

Kolom komponen gambar merupakan penjabaran dari kolom "produk" dari Tabel 1. Jika setiap komponen penilain proses dipisahkan maka dapat diketahui nilai-nilai rerata kelas dari setiap komponen gambar dan nilai capaian KKM sebesar 75,94 (dibulatkan 76).

Tabel 2. Hasil refleksi dan perbaikan siklus1

\begin{tabular}{|c|c|c|}
\hline No & Hasil Refleksi Siklus 1 & Langkah perbaikan/revisi \\
\hline 1. & $\begin{array}{l}\text { Boros waktu karena dosen dalam diskusi } \\
\text { terlalu lama sehingga banyak mahasiswa } \\
\text { yang menunggu ingin segera presntasi. }\end{array}$ & $\begin{array}{l}\text { Dosen mempersempit waktu penjelasan dan } \\
\text { presntasi segera dapat dilakukan }\end{array}$ \\
\hline 2. & $\begin{array}{l}\text { Mahasiswa cenderung kurang cepat } \\
\text { dalam mendesain karena kemampuan } \\
\text { mahasiswa beragam dalam hal desian. }\end{array}$ & $\begin{array}{l}\text { Dosen memberikan penjelasan dari substansi } \\
\text { gambar rangkaian dan menyebutkan kreteria } \\
\text { keberhasilan gambar PCB. }\end{array}$ \\
\hline 3. & $\begin{array}{l}\text { Kemampuan inqury dan penguatan } \\
\text { kepada mahasiswa belum terbentuk. }\end{array}$ & $\begin{array}{l}\text { Dosen memberikan alokasi waktu lebih banyak } \\
\text { pada mahasiswa untuk mengerjakan proyek. Dosen } \\
\text { memberikan reward bagi yang dapat menyelesaikan } \\
\text { job lebih awal. }\end{array}$ \\
\hline
\end{tabular}

Tujuan plan pada siklus 2 adalah untuk perbaikan, diantaranya: (1) dosen akan mempersempit waktu penjelasan meteri desain web surviellence dan lebih membaur dengan mahasiswa melalui personal tutorial; (2) meningkatkan sensitifitas untuk membaca kemampuan mahasiswa yang memiliki daya tangkap mahasiswa rendah; (3) secara teknis dosen memberikan penjelasan dari substansi proyek web survillence; (4) dosen menjelaskan cara-cara cepat mendesain menggunakan Proteus melalui personal tutorial; dan (5) dosen menjelaskan cara-cara melakukan simulasi dengan ISIS dan ARES secara singkat lalu dosen melakukan personal tutorial agar materi lebih mudah tersampaikan. Siklus 2 dapat dilaksanakan dalam 2 pertemuan pada 21 April 2017 dan 28 April 2017. Hasil pelaksanaan PjBL pada siklus 2 disajikan pada Tabel 3.

Tabel 3. Nilai (rerata kelas) PjBL pada siklus 2

\begin{tabular}{lllll}
\hline Unsur Gambar & Siklus 1 & Siklus 2 & $\begin{array}{l}\text { Peningkatan } \\
\text { Index }\end{array}$ & Persen (\%) \\
\hline Kreativitas (45) & 31,30 & 32,43 & 1,13 & $3,61 \%$ \\
Kebenaran (15) & 12,15 & 12,37 & 0,22 & $1,80 \%$ \\
Kerapihan (15) & 12,42 & 12,71 & 0,29 & $2,33 \%$ \\
Waktu (25) & 20,06 & 20,17 & 0,11 & $0,54 \%$ \\
Rerata & 75,94 & 77,69 & 1,75 & $8,28 \%$ \\
\hline
\end{tabular}


Tabel 3 merupakan penjabaran dari pengamatan produk gambar/hasil gambar mahasiswa yang di dalamnya memenuhi empat unsur kreativitas, kebenaran, kerapihan dan waktu yang mengalami kenaikan $8,28 \%$. Kegiatan reflect (Siklus 2) dilakukan mirip dengan reflect (Siklus 1). Namuan ada perbedaan, dari sisi pemfokusan yaitu pada siklus 2 ini dittitik beratkan pada aspek kerapihan dan waktu. Hasil refleksi siklus 2 disajikan pada Tabel 4.

Tabel 4. Hasil kegiatan refleksi siklus 2 dan langkah perbaikan

\begin{tabular}{|c|c|c|}
\hline No. & Hasil Refleksi Siklus 2 & Langkah perbaikan/revisi \\
\hline 1. & $\begin{array}{l}\text { Dosen terlihat letih saat melakukan banyak personal } \\
\text { tutorial, namun mahasiswa terlihat lebih mudah } \\
\text { melakukan praktik menggambar dan frekuensi } \\
\text { bertanya semakin berkurang. }\end{array}$ & $\begin{array}{l}\text { Dosen disarankan untuk membagi } \\
\text { tugas tutorial dengan menunjuk } \\
\text { beberapa mahasiswa yang dianggap } \\
\text { mampu menyelesaikan lebih awal } \\
\text { untuk melakukan peer tutorial. }\end{array}$ \\
\hline 2. & $\begin{array}{l}\text { Mahasiswa bersemangat mengerjakan job dengan } \\
\text { cepat, ketika dosen kembali memberikan penilaian } \\
\text { berdasarkan prioritas waktu. }\end{array}$ & $\begin{array}{l}\text { Langkah ini terus digunakan hingga } \\
\text { tercapai target peningkatan aspek } \\
\text { kerapihan dan waktu }\end{array}$ \\
\hline 3. & $\begin{array}{l}\text { Ada kecenderungan mahasiswa yang berhasil } \\
\text { menyelesaikan praktikum ke } 1 \text { dan } 2 \text { lebih awal untuk } \\
\text { praktikum ke } 3 \text { dan } 4 \text {, serta kemampuan inqury dan } \\
\text { penguatan antar mahasiswa mulai terbentuk. }\end{array}$ & $\begin{array}{l}\text { Dosen memberikan perhatian lebih } \\
\text { pada mahasiswa yang lamban dalam } \\
\text { menyelesaikan job untuk dilakukan } \\
\text { peer tutorial. }\end{array}$ \\
\hline 4. & Ada 2 mahasiswa belum menyelesaikan proyek. & Dosen menganggap cukup, bahwa \\
\hline 5. & $\begin{array}{l}\text { Model of environment: kelas lebih berkembang saat } \\
\text { dilakukan penilaian prioritas penyelesain. Akan tetapi } \\
\text { kelas cenderung lebih lama mengerjakan skematik } \\
\text { dan simulasi di praktikum ke } 2 \text {. }\end{array}$ & $\begin{array}{l}\text { kemampuan mengembangkan } \\
\text { proyek secara kualita sudah sesui } \\
\text { kriteria capaian. Oleh karenanya } \\
\text { siklus dianggap cukup. }\end{array}$ \\
\hline
\end{tabular}

Dalam penilaian keterampilan pengembangan proyek ada empat unsur yang menjadi pokok penilaian yaitu kreativitas gambar (45), kebenaran (15), kerapihan (15) dan waktu (25). Nilai angka di belakang kriteria menunjukan batasan maksimal nilai, sehingga jika di total mencapai 100 poin. Keseluruhan dari hasil penilaian dari prasiklus hingga siklus 2 tersaji pada Tabel 5 .

Tabel 5. Nilai (rerata kelas) pengembangan proyek pada semua siklus

\begin{tabular}{lccc}
\hline Komponen Gambar & Pra Siklus & Siklus 1 & Siklus 2 \\
\hline Kreativitas (45) & n/a & 31,30 & 32,43 \\
Kebenaran (15) & & - & $\uparrow 1,13(3,61 \%)$ \\
Kerapihan (15) & n/a & 12,15 & 12,37 \\
& & - & $\uparrow 0,22(1,80 \%)$ \\
Waktu (25) & n/a & 12,42 & 12,71 \\
& & - & $\uparrow 0,29(2,33 \%)$ \\
Jumlah Nilai Rerata & n/a & 20,06 & 20,17 \\
& & - & $\uparrow 0,11(0,54 \%)$ \\
& n/a & 75,94 & 77,69 \\
& & - & $\uparrow 1,75(8,28 \%)$ \\
\hline
\end{tabular}


Khusus untuk pra siklus tertulis n/a (not available) hal ini disebabkan pada pra siklus peneliti tidak melakukan penilaian apapun kecuali pengamatan untuk tujuan pemetaan masalah. Jumlah nilai rerata dari siklus 1 $(75,94)$ ke siklus 2 naik menjadi 77,69 atau mengalami kenaikan sebesar naik $\uparrow 1,75$ $(8,28 \%)$. Implikasi dari tiga unsur antara siklus, PjBL dan keterampilan gambar terlihat dari hasil gambar. Hasil gambar yang memenuhi empat unsur (kreativitas, kebenaran, kerapihan dan waktu) merupakan satu pekerjaan yang tidak dapat diuraikan secara terpisah. Dalam pelaksanaan pembelajaran (siklus) unsur kebenaran gambar menjadi hal terpenting dan sebagai prasyarat agar mahasiswa dapat melakukan proyek selanjutnya. Setelah masuk ke proses layout maka unsur komposisi dan kerapihan menjadi poin penting, dari keseluruhan unsur kebenaran dan kerapihan, maka waktu penyelesaian menjadi penentu. Artinya secara kasar-pun dosen dapat melakukan assessment bahwa mahasiswa yang sudah mampu menyelesaikan secara cepat dimungkinkan unsur komposisi dan kerapihan telah tercapai. Akan tetapi assessment semacam ini tidak disarankan, dosen tetap harus menilainya sesuai dengan keempat unsur yang telah dirumuskan.

Implikasi yang muncul dari hasil pelaksanaan dalam PTK adalah bahwa dosen melalui metode $\mathrm{PjBL}$ mampu membawa dampak positif, berhasil meningkatan keterampilan mendesain suatu proyek web survillence melalui metodePjBL. Nilai rerata mahasiswa mampu mencapai 77,69 yang ditempuh dalam waktu 4 kali pertemuan (2 siklus).

\section{SIMPULAN}

Proses peningkatan kemampuan menyelesaikan proyek MK Telekomunikasi Bergerak dan Seluler dapat ditingkatkan melalui Project Based Learning (PjBL) yang terdiri dari enam tahap; questioning, scheduling, designing, monitoring, assessing, dan evaluating. Proses peningkatan didapat berdasarkan proses dari satu tahapan ke tahapan lain. Hasil pelaksanaan pembelajaran MK Telekomunikasi Bergerak dan Seluler berbasis model Project Based Learning mampu meningkatkan daya-upaya mahasiswa dalam mendesain proyek. Dalam waktu empat pertemuan menyelesaikan satu proyek, dengan hasil evaluasi kemampuan meningkat 1,75 poin atau setara $8,28 \%$.

\section{DAFTAR PUSTAKA}

Abdul Majid. 2013. Strategi pembelajaran. Bandung: PT. REMAJA Rosdakarya.

Adler, J., Azhar M., Supatmi S. 2013. Identifikasi Suara dengan MATLAB sebagai Aplikasi Jaringan Syaraf Tiruan.

Ariyadi, R., Purnomo M. H., Ramadijanti N., \& Dewantara B. S. 2010. Pengenalan Rasa Lapar Melalui Suara Tangis Bayi Umur 0-9 Bulan dengan Menggunakan Neural Network.

Arsyad, A. 2011. Media Pembelajaran. Jakarta: PT Raja Grafindo Persada.

Bermawy Munthe. 2009. Desain pembelajaran. Yogyakarta: PT. Pustaka Insan Madani.

Cahyani, N.I. 2010. Penggunaan Power Point untuk Meningkatkan Hasil Belajar Mahasiswa pada Mata Pelajaran IPA Kelas IV SD Negeri 1 Karangwader Kecamatan Penawangan Kabupaten Grobogan TA 2009/2010.

Chaeruman. 2008. Mengembangkan Sistem Pembelajaran dengan Model ADDIE. Jakarta: PT Remaja Rosdakarya.

Daryanto. 2010. Media Pembelajaran. Yogyakarta: Gava Media.

Djuwairiyah, Siti. 2007. Penerapan Metode Belajar Aktif Sebagai Upaya Membantu Meningkatkan Prestasi Belajar Pada Siswa Kelas 6. http://media.diknas.go.id/media/docum 
ent/5302.pdf. diakses pada tanggal 30 Oktober 2017 Pukul 11.45 WIB.

Eveline Siregar \& Hartini Nara. 2010. Teori belajar dan pembelajaran. Bogor: Ghalia Indonesia.

Fausett, L. 1994. Fundamental of Neural Network. New Jersey: Prentince Hall International Edition.

Hanafiah, Nanang. \& Cucu, Suhana. 2009. Konsep Strategi Pembelajaran. PT Refika Aditama. Bandung.

Indriana, D. 2011. Ragam Alat Bantu Media Pengajaran. Yogyakarta: Diva Press.

Kunandar. 2014. Penilaian autentik. rev.ed. Jakarta: PT Raja Grafindo Persada.

Made Wena. 2009. Strategi pembelajaran inovatif kontemporer: suatu tinjauan konseptual operasional. Jakarta: Bumi Aksara.

Masayu Leylia Khodra. 2010. Reinforcement learning. 2003: hal. 3-9. Departemen Teknik Informatika Institut Teknologi Bandung.

Muh. Rais. 2010. Project based learning: Inovasi pembelajaran yang berorientasi soft skills. Makalah disajikan sebagai Makalah Pendamping dalam Seminar Nasional Pendidikan Teknologi dan Kejuruan Fakultas Teknik Universitas Negeri Surabaya tahun 2010. Surabaya: Unesa.

Muhammad Thabrani \& Arif Mustofa. 2013. Belajar dan pembelajaran. Yogyakarta: Ar-Ruzz Media.

Nanang Hanafiah \& Cucu Suhana. 2009. Konsep strategi pembelajaran. Bandung: PT. Refika Aditama.

Nana Sudjana. 2011. Penilaian hasil proses belajar mengajar. Bandung: PT.Remaja Rosdakarya.

Nana Syaodih Sukmadinata. 2012. Metode penelitian pendidikan. Bandung: PT Remaja Rosdakarya.

Oemar Hamalik. 2012. Proses belajar mengajar. Jakarta: Bumi Aksara.
Pressman, R.S. 2007. Rekayasa Perangkat Lunak: Pendekatan Praktisi (Buku1).

Martin, J. 1990. Information Engineering: Book II - Planning and Analysis, Prentice-Hall. Yogyakarta: Andi.

Rusman. 2012. Belajar dan Pembelajaran Berbasis Komputer: Mengembangkan Profesionalisme Dosen Abad 21. Bandung: Penerbit Alfabeta.

Setya Purnawan. 2010. Peningkatan Motivasi Belajar Penerapan Dasar-dasar Elektronika melalui Pembelajaran Kooperatif Team Games Tournament (TGT) di SMK Muhammadiayah Prambanan. Skripsi: Tidak diterbitkan

Smaldino, E.S., Russel, J.D., Heinich, R., 2004. Instructional Media and Technologies for Learning ( ${ }^{\text {th }}$ Edition). New Jersey: Pearson Merril Prentice Hall.

Sugiyono. 2013. Metode penelitian kuantitatif kualitatif dan RnD. Bandung: Alfabeta.

Sukardjo \& Lis Permana Sari. 2009. Metodologi Penelitian Pendidikan Kimia. Yogyakarta: FMIPA UNY.

Suharsimi Arikunto. 2008. Penelitian tindakan kelas. Jakarta: PT Bumi Aksara.

Sukardi. 2013. Metodologi penelitian pendidikan. Jakarta: PT. Bumi Aksara.

Syaiful Bahri Djamarah \& Aswan Zain. 2006. Strategi belajar mengajar. Jakarta: PT. Rineka Cipta.

Trianto. 2014. Mendesain Model Pembelajaran inovatif, Progresif, dan Kontekstual. Jakarta: Prenadamedia Group.

Winataputra, U. S. dkk. 2008. Teori belajar dan pembelajaran. Jakarta: Penerbit Universitas Terbuka.

Wiryadinata, R. 2005. Simulasi Jaringan Syaraf Tiruan Berbasis Metode Backpropagation Sebagai Pengendali Kecepatan Motor DC 
Ahmad, Nurkhamid, Totok, Muslikhin \& Purno, Peningkatan keterampilan mahasiswa dalam pengembangan ... 177 